\title{
GAINING SOCIALLY SUSTAINABLE CITIES THROUGH SHARING INDOOR SPACES FOR VOLUNTARY ACTIVITIES: THE CASE OF TRONDHEIM, NORWAY
}

\author{
DANIELA BAER ${ }^{1}$, DENIZ AKIN ${ }^{2}$, LARS ARNE B $\emptyset^{1}$, JACQUELINE FLOCH ${ }^{1}$, \\ TROND HALVORSEN ${ }^{1} \&$ KARIN HØYLAND ${ }^{1}$ \\ ${ }^{1}$ SINTEF, Norway \\ ${ }^{2}$ Norwegian University of Science and Technology, Norway
}

\begin{abstract}
The influence of indoor shared spaces in neighbourhoods on voluntary activities is barely investigated in literature. Conversely, the impact of space on social activities is widely recognized in literature and an impact on voluntary activities is also identified - but it focuses more on wider geographical scopes, comparing regions. Little is known so far about which characteristics of space and governance structures influence voluntary work on a smaller geographical level - such as a city or neighbourhood. In a case study conducted in the city of Trondheim, Norway and the neighbourhood of Saupstad, we elaborate an understanding on the influence of shared spaces on voluntary work. We ask which characteristics of the shared spaces and governance structures foster or limit voluntary activities. Our study is based on observation and qualitative interviews with providers of shared indoor spaces for voluntary work, voluntary organizations and the stakeholders involved (city administration, neighbourhood management, etc.). We applied a multi-scale research approach at a city, neighbourhood and building level to identify challenges and enablers on all urban scales. We have chosen a case study approach for an in-depth qualitative analysis to identify these factors. Our research shows that the physical characteristics of shared spaces such as location, accessibility and facility equipment play an important role in voluntary activities. In the worst case, voluntary work had to be stopped when the shared space was no longer available. On the other hand, there is a great potential of sharing spaces not yet provided for voluntary activities, due to lacking incentives, restrictions on use of these spaces and a lack of cooperation between providers of shared spaces. In particular, the existing governance structure at a neighbourhood level plays an important role in fostering space-sharing and enabling voluntary activities.
\end{abstract}

Keywords: sustainable development, neighbourhood, volunteering, sharing space, third places, case study

\section{INTRODUCTION}

To foster social sustainability through participation in community life is set high on the urban agenda. In this context, the role of voluntary work is to provide arenas for social participation. As voluntary organizations are equipped with limited financial resources, their work is often reliant on the availability of cheap spaces to offer their activities. Spaces in use for voluntary work are thereby often shared spaces. We define shared spaces as spaces that are mainly used for public or private purposes, and additionally, when not in use for their original purpose, are shared with other forms of use, e.g. voluntary activities. Examples of that are schools where classrooms, the cafeteria or the sports hall is used for other purposes when the regular school day is over [1]. Our study focuses on shared indoor spaces, as there is little known about their impact on voluntary activities. Many voluntary activities - especially in Norway - are happening indoors due to climatic conditions and the context and demands of the voluntary activity itself. Little is known about how the availability and characteristics of these shared spaces influence voluntary work.

Social sustainability in society is about the ability of the entire community, or of community at the neighbourhood level, to maintain and reproduce themselves at an 
acceptable level of functioning. This is linked to "social capital" and "social cohesion" as concepts that encompass social networks, norms of reciprocity and social organizational forms and result in social behaviour [2], [3]. Voluntary organisations play a strong role in community building as supportive institutional structures [4]. Their presence or absence do affect the levels of social participation, and thereby the formation of social capital [5], [6]. We adopt Wilson's [7] definition of volunteering as "any activity in which time is given freely to benefit another person, group, or organization". In our studies we focus on formal voluntary activities that are not ad-hoc, but following institutional routines in the way that they occur regularly [8].

Several studies have focused on the impact of geographical factors on voluntary activities. Kendall and Knapp [9] for the UK and Salamon [10] for the US identified an uneven geographical spreading of voluntary activities between regions and thereby the formation of social capital in local communities. An urban-rural divide in volunteering activities was investigated by Hooghe and Botterman [11] and the impact of ecological factors (city and neighbourhood level) on sociodemographic differences in volunteering by Musick and Wilson [12]. Both studies identify an implication of space and local context on voluntary activities. Dury et al. [13] run a statistical analysis based on data for 141 municipalities in Belgium and identified that factors such as neighbourhood connectedness, neighbourhood satisfaction, home ownership, and presence of services predict voluntary influence and voluntary engagement of citizens of older age at the neighbourhood level. While all these studies focus on the impact of geographical factors at a regional, municipal and neighbourhood level, the question of how the concrete place for voluntary activities influences the activities remains under-explored so far.

Some studies have shown that there is a high impact of space on social activities. The sociologist Ray Oldenburg introduced the concept of third places with his book "The great good place" [14] and described them as spaces for social surroundings separate from the two usual social environments of home ("first place") and the workplace ("second place"). Oldenburg identified 10 arguments on how third places strengthen communities, from strengthening political participation to fostering communication and unifying the neighbourhood. Empirical studies strengthen the argument on how local meeting places foster community building and social relations in a neighbourhood [15]. Following Oldenburg's argumentation [14], third spaces must be highly accessible and proximate for many (walking distance), be welcoming and comfortable and involving regulars - those who habitually congregate there to serve their role in fostering community building. Oldenburg [16] has blamed the "unfunctional zoning" praxis in urban planning that leads to the absence of third places in neighbourhoods and Butler and Diaz [17] point out that especially suburban neighbourhoods are missing adequate third places.

We argue that shared spaces for voluntary activities can serve as third places within a neighbourhood. Addressing the importance of third places, meeting places and voluntary activities for community building and bearing in mind the research gap on the characteristics and factors influencing voluntary activities in shared spaces, we address the following research questions in this paper: What is the role of stakeholders involved to provide shared spaces for voluntary activities? What factors influence the availability and use of shared space for voluntary activities?

\section{METHODOLOGY}

We have chosen a qualitative approach to address the research gap on shared spaces and its impact on voluntary activities. A case-study approach was chosen for an in-depth analysis of the topic, aligned by qualitative methodologies, i.e. observations and qualitative interviews. 
Semi-structured interviews were conducted both as individual and as focus group interviews between 2017 and 2019. The minutes were analysed with the help of qualitative content analysis [18]. We interviewed 9 persons who are involved in space sharing in the case study area of Saupstad in the city of Trondheim. The main inclusion criteria is that they either provide or use shared spaces for voluntary activities, or play an intermediate role by facilitating sharing or voluntary activities (see Table 1). The subjects were identified by applying the snow-balling technique, starting with the coordinator at the Voluntary Centre in Saupstad. The coordinator was chosen because we expected her to have the broadest insight in the research field in the case study.

In addition to the interviews, we conducted observations in two workshops within the neighbourhood of Saupstad to gain a broader insight in our research topic and to gather additional data. The first one was a workshop on volunteering in Saupstad facilitated by the authors (SINTEF and the Norwegian University of Science and Technology (NTNU)) on 23 January 2018 (O1). The second was the innovation camp at Heimdal high school (a yearly event) where students developed ideas to solve local challenges, in our case room sharing. The local challenge was provided by the lead author (8/9 March 2018) (O2). Data gathered through interviews or observations are referred to using the abbreviations I (number) for interviewees and $\mathrm{O}$ (number) for observations (Table 1), for convenience and to provide anonymity.

\section{TRONDHEIM AS CASE STUDY}

We applied a multi-scale research approach on the city and neighbourhood level to identify challenges and enablers on both urban scales on shared spaces for voluntary activities. The following section describes the general background of our case study of Trondheim and its neighbourhood of Saupstad, as well as stakeholders involved.

Trondheim is Norway's third biggest city, situated in central Norway where the river Nidelva meets the Trondheim fjord. The city is known for its cathedral and having the largest university in Norway (NTNU). It has an important harbour and a large scientific community, with several research institutions and high-tech industry based in the city. Additionally, Trondheim serves as a public transport and logistic hub in Central Norway and Mid-Scandinavia. Trondheim has a population of 205,163 people (January $1^{\text {st }} 2020$ ), with the wider region exceeding 280,000 inhabitants.

Table 1: Interviews conducted in the case study of Trondheim and Saupstad.

\begin{tabular}{|l|c|c|c|c|}
\hline \multirow{2}{*}{ Interviewees } & \multicolumn{2}{|c|}{ Number and role of interviewees } & \multirow{2}{*}{$\begin{array}{c}\text { Abbreviation } \\
\text { for } \\
\text { Interviewees }\end{array}$} \\
\cline { 2 - 4 } & Coordinator & Provider & User & I1 \\
\hline Voluntary centre coordinator & 1 & - & - & I2, I3, I4 \\
\hline $\begin{array}{l}\text { Group interview with } \\
\text { volunteers }\end{array}$ & - & - & 3 & I5 \\
\hline Volunteer & - & - & 1 & I6 \\
\hline $\begin{array}{l}\text { Coordinator of a municipal } \\
\text { neighbourhood improvement } \\
\text { program }\end{array}$ & 1 & & & I7 \\
\hline Local soccer club & - & 1 & - & I8 \\
\hline Housing association & - & 1 & - & I9 \\
\hline Booking portal for Trondheim & 1 & - & - & \\
\hline
\end{tabular}


Saupstad is a neighbourhood located in the southern part of Trondheim. It is part of the larger municipal district of Heimdal. Built in the late 1960s, Saupstad is one of the largest suburbs in Trondheim with regard to size and the most populous one, gaining for the highest density rates in Trondheim [19]. Saupstad has been considered a socially disadvantaged district, in comparison with the rest of Trondheim and nationally, due to a set of reasons. First, the neighbourhood has a relatively poor record in respect to income, education and disability benefits among its inhabitants. Second, the neighbourhood has a high unemployment rate and high number of households living below the poverty line in comparison with other areas of Trondheim. Third, the district has been considered unfavourable due to the poorly organized centre area which is characterized by large parking areas, little green space and few meeting places [20]. Due to these challenges, the district has captured the attention of politicians, architects and urban planners among other experts [21].

To address these challenges, a neighbourhood improvement program called "områdeløft" (2012-2020) was initiated in the neighbourhood to align state and municipal funding in applying measurements in order to improve living qualities [20]. The overall objectives of the program are: to promote quality of life and health; building competence in the children and youth which prepares them for the challenges of the future; building a sustainable neighbourhood with a variety of building structures and good quality of infrastructure and public space; to build a district with a variety of meeting areas and the possibility for community building. The "områdeløft" program is designed in a way that aims to mobilize the neighbourhood's own resources, entailing the inclusion of the local community and incorporation of their needs and demands. In this respect, a set of social networks are established between housing cooperatives, residents, associations, unions and volunteer organizations [20].

\section{RESULTS}

In this section we present the findings with regard to space sharing on a city, neighbourhood and building level in our case study of Trondheim.

\subsection{Shared indoor spaces for voluntary activities in the city of Trondheim}

The municipality of Trondheim has its own strategy to share public spaces for the public, including voluntary activities. The shared public spaces are divided in three categories; outdoor public spaces, indoor public spaces and sport facilities (indoor and outdoor) with different entities involved to facilitate the sharing of spaces.

For the sharing of indoor public spaces, the municipal parliament has approved an agreement in February 2015 to foster indoor space sharing of public buildings when the spaces are not in use [22]. These buildings include schools, kindergartens, health and social care facilities, libraries and rooms in use by the cultural department of Trondheim municipality. Indoor spaces can be used by voluntary organizations free of charge. Extra costs for cleaning or maintenance may possibly be charged. The sharing of rooms is prioritized "to provide municipal services to the citizens of Trondheim" and additionally with regard to the users of the shared rooms. Teaching courses are prioritized, followed by activities for children and youths under 25 years or seniors over 65 years, and finally activities that foster well-being and a better community life for the local neighbourhood the buildings are located in.

The routines for sharing of spaces vary with regard to the length of renting out. A permanent loan of rooms over the period of 9 months from September to June in the following year is facilitated by a unit called the event office (Arrangementkontoret), organized by the 
municipal cultural department. For the distribution of shared spaces, a separate committee is established, and the involved municipal units are consulted [22]. Short term loan of spaces is facilitated and decided directly by the leader of the unit which is responsible for the building which the spaces are located in. This is, e.g., the principal of a school building or an appointed employee.

The event office consists of 8 employees, where one is dedicated to take care of and further develop the sharing of public spaces. Within this unit, a web-based booking platform called "Bookingbasen" was developed to facilitate the sharing of public indoor spaces. Voluntary organisations have to register in a separate base called "Aktørsbasen" to be approved for renting spaces. Within the booking platform many public indoor spaces are registered, and users of the platform can search for spaces and get information of the space and its facilities [23].

It took several years to build up this platform, especially as not every possible provider of indoor spaces was motivated to share them. That's why Trondheim municipality invented a revenue system. Based on the number of hours shared spaces is used by voluntary organizations, the involved public entity will get a financial cashback. These financial benefits are perceived as lucrative by the public entities and have increased their motivation to share spaces. This has resulted in a higher amount of provided shared public spaces within the online booking platform.

In general, the provision of shared spaces is crucial for voluntary organizations in order to provide their activities, as there were observed several cases where the voluntary activity had to be stopped because the shared space was no longer provided. For many it is crucial for what they deal with. Many cannot continue with the activities without getting free spaces, as an interviewee pointed out: "We notice that when something happens and the voluntary activities can no longer be where they used to be, [...] we sometimes see the consequence that they have to put down the offer. This is a huge pity, and it says something about how important the room sharing is" (19). Additionally, it is crucial that spaces are available in geographical closeness to the main operation area of the voluntary activities, due to challenges to provide the activity at a space far away.

The design of the building influences the possibilities to provide shared spaces. On the one hand, spaces that are located at the outer part of a building, as e.g. sport halls at schools, are easily accessible. Spaces located further into the building crop are often more difficult to access with i.e. regard to length of way or entrance control. On the other hand, the use of a shared space often limits the use of a close-by shared space. An example is the use of a space by a choir when this is too loud to make the close-by room usable.

A building that is thoroughly planned and designed for multiple use makes it easier to share spaces. The zoning of spaces in new school buildings in Trondheim is defined as a good example (I9). Spaces most attractive for sharing, such as music room, cafeteria, aula and sport halls, are clustered and located near an entrance.

The entrance control is indicated as a challenge in some buildings and for some voluntary activities. Especially when access to the building is provided through a key or key card, and this is limited available. Voluntary activities where a lot of people participate and the participants need to access the building on varying timeslots as e.g. swimming classes, often challenges the organizers of the activity. The organizers are challenged to provide access to the building for all participants arriving and at the same time run the activity. The authors observed voluntary activities, where participants had to wait for a long time outside the building due to missing access. Trondheim municipality therefore started a project in 2019 to investigate the possibilities of installing smart locking systems in their buildings. 
Trondheim municipality has an interest to get data on the occupation of shared spaces to optimize the distribution of spaces to voluntary activities.

\subsection{Shared indoor spaces Space-sharing in the neighbourhood of Saupstad}

\subsubsection{Stakeholders involved and their shared spaces}

In total, we could identify nine spaces or group of spaces located within 7 buildings that are provided for voluntary activities in Saupstad (see Fig. 1). In the following, the stakeholders and their role and interest in space sharing is described.

The Volunteering Centre of Saupstad (VCS) was established in 2004, and forms one of the 11 "volunteering centres" in Trondheim. The centre is own by Trondheim Red Cross and supported financially by the Municipality of Trondheim. It has one full-time employee who is the general manager of VCS. Currently, there are around 80 people volunteering for the centre that arranges various activities following local needs and demands. The need for an activity can be identified and suggested by a local neighbourhood partner, a volunteer or the general manager. The provision of activities relies on the willingness of volunteers to support and carry out the activities. Therefore, the range of activities tend to focus on the user groups that engage in volunteering at the volunteering central. The major user-group of the VCS is retirees, and unemployed residents. VCS offers activities run by volunteers, such as tour-group, dancing group (Friskusdans), choir, accompanying activity (for those who need help to go to shopping or to the hairdresser etc). VCS focus in their work on "producing meeting places" (I1) for people in Saupstad and do not own spaces, but do facilitate sharing of spaces for others, i.e. mainly spaces within TK's buildings such as the meeting room in the library.

VCS is facilitating three types of shared indoor spaces for voluntary activities, located in one building, in the heart of the neighbourhood. Firstly, the two small meeting rooms located right next to the office of the VCS. Secondly, the seating area of the Neighbourhood Café [Bydelscafe] can be used free of charge for voluntary activities after closing time at $3 \mathrm{pm}$. Thirdly, the health care centre has an own open-designed meeting room, E-stua, which is used, for example, for Bingo activities, including by elderly inhabitants, school students and volunteers.

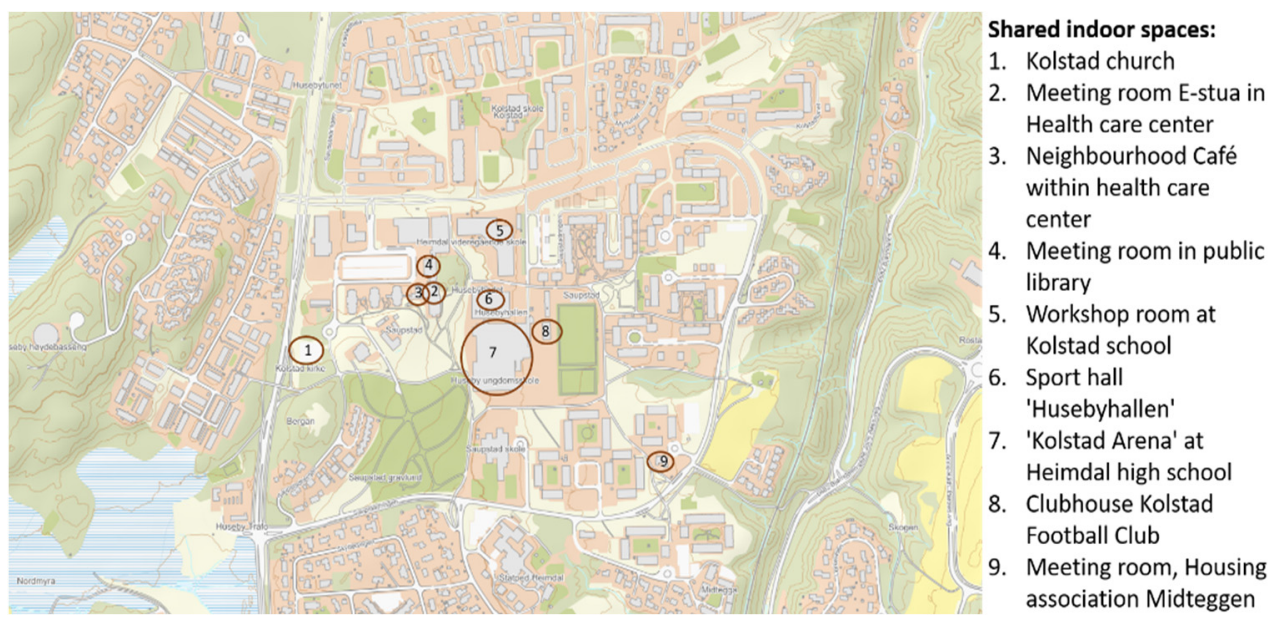

Figure 1: Location of shared indoor spaces in the neighbourhood of Saupstad, Trondheim. 
Kolstad Football Club (KFC) was founded in 1972. The club is administrated by a board and the two full-time employees who are responsible for the club operations and day-to-day management. A great deal of people who engage with other tasks for the club are volunteers such as, trainers, people who work in the food-counter during games, and those who sell lottery tickets to raise money for the club. There are also volunteers called upon when the football field is to be cleaned from snow, or to do other kind of tasks that require collective action (in Norwegian: "dugnad"). The main user groups of KFC are children, youngsters and families who have children. KFC also appears to be a local actor that provides service and activities to everyone, not only children and youngsters. In cooperation with Trondheim Municipality, the club runs "Utlånssentral" which lends out outdoor and sport equipment to anyone free of charge. The clubhouse of the KFC is rented out for voluntary activities, and the manager of the club sees the providing of free spaces as a worthful contribution to local community life.

Midteggen housing cooperative (MHC) (borettslag) is established in 1973. MHC is composed with 24 buildings comprising 472 apartments. The residents of the housing complex are families with and without children, retirees, people with minority backgrounds. The management board of MHC, represented by volunteering residents, arranges a variety of activities for this mosaic of residents with different backgrounds.

Kolstad church is a parish church built in 1986 in the Saupstad area. The church has several rooms for rent suitable for different events: the church hall rooms up to 30 persons, the parish hall up 80 people, the activity room in the basement up to 20 persons, and the church itself up to 460 persons. The rooms can be rented against a small fee. The public activities taking place in the church are listed on the congregation web site,

Trondheim municipality (TK) owns several buildings in the Saupstad neighbourhood, but only spaces within the Kolstad school and Huseby Hall are provided for sharing through the booking base. Other spaces in TK's buildings, such as the Neighbourhood Café and meeting room E-stua in the health care centre, are facilitated for sharing through local channels and the voluntary centre, and are not within the booking platform.

Kolstad handball (KH) was created in 1972, along with the rest of the Kolstad Sports Club. They have gradually developed into a financially independent alliance. However, they work closely with Kolstad Football Club in order to give children extensive sports opportunities throughout the year. Kolstad Handball is renting out spaces as the sportshall and other rooms within the Heimdal High School from the Trøndelag County. They share these spaces with other voluntary and commercial activities. Depending on the usage, they charge a fee to re-finance their rent. As the high school was only completed and opened at the end of our study time, these rooms are listed just to give a complete overview of the availability of shared spaces but are not investigated in depth in our studies. Table 2 gives an overview and description of the shared spaces provided in Saupstad.

\subsubsection{Factors influencing the availability and use of shared spaces in Saupstad}

During our interviews and observations in the neighbourhood of Saupstad, we could identify several factors that influence the availability and use of shared spaces for voluntary activities. These factors are presented in the following.

The costs of renting out spaces for voluntary activities influence the choice of which rooms are used. Regarding spaces available, interviewees point to spaces within the centrally located shopping centre, which they rate as positive due to a high visibility, but are too expensive. "They rent it out but take $200 €$ a day [...]. In the end, we borrow the neighbourhood cafe for free, and it think that is better" (I3). 
The users of shared spaces express that they often miss specific facilities at these spaces. E.g. the neighbourhood café is perceived as a nice room with a good atmosphere, but due to regulations the kitchen facilities cannot be used by volunteers. Rudimentary things like cooking coffee for a meeting then entails a lot of effort.

The interviewees point out that most of the locations for voluntary activities are located within the central area of Sausptad and thereby difficult to reach - especially for elderly. Even in Saupstad, it is also a challenge that it is far up to the "centre" (I2).

People from neighbouring areas as Romolslia, have even greater difficulty accessing the voluntary activities: "It's completely dead down in Romolslia. So, it's almost just older people living there, up in the blocks there. They have no place to go, but they could, it's just too far for them to go up here. It's uphill all the way and no buses go there. Yes, it is a hopeless place to live" (I4).

They point to the fact that additionally to the distance from home to the activity, many of the apartment blocks do not have elevators. People with mobility challenges do not have the possibility to attend voluntary activities.

One solution applied to minimize the distance between the location of the voluntary activity and the residents, was the establishment of the "hyggetreff" activity - a weekly open meeting to talk - at the location of the housing association. Due to an agreement between the VCS and the housing cooperation, the use of the facilities is free of charge. Residents of the cooperation are always free to use the facilities, but others are charged. The interviewee from the housing cooperation pointed out, that they did not charge for the rent as they suppose many of the participants of the "hyggetreff" will be from their residents, due to the short distance. Due to the location of the activity at another shared space than the activities normally take place, the volunteers state that other persons participate in the activities. "Other people come to [meeting] 'hyggetreff' the in Revegården. Must be very short distance to events. Haven't seen these [people] on other activities" (O1).

Table 2: Description of shared spaces in the neighbourhood of Saupstad.

\begin{tabular}{|l|c|c|c|}
\hline \multicolumn{1}{|c|}{ Shared spaces and owners } & Facilities & Price & Providers \\
\hline 1. Kolstad church & $\begin{array}{c}3 \text { rooms of } \\
\text { different sizes }\end{array}$ & $€ 120-180$ & Direct \\
\hline $\begin{array}{l}\text { 2. Meeting room E-stua in Health } \\
\text { care centre, TK }\end{array}$ & 1 room & free & Via VCS \\
\hline $\begin{array}{l}\text { 3. Neighbourhood Café within } \\
\text { Health Care centre (TK) }\end{array}$ & 1 room & free & Via VCS \\
\hline 4. Library meeting room, TK & 1 room & free & Via VCS \\
\hline $\begin{array}{l}\text { 5. Huseby school workshop room, } \\
\text { TK }\end{array}$ & 1 room, 250 qm & free & $\begin{array}{c}\text { TK Booking- } \\
\text { base }\end{array}$ \\
\hline $\begin{array}{l}\text { 6. Husebyhallen, TK } \\
\text { 7. Heimdal high school/Kolstad } \\
\text { Arena, County of Trøndelag }\end{array}$ & $\begin{array}{c}\text { sport hall, several } \\
\text { smaller rooms }\end{array}$ & variable & $\begin{array}{c}\text { Via KH } \\
\text { base }\end{array}$ \\
\hline 8. Kolstad club house, KFC & $\begin{array}{c}1 \text { room with } \\
\text { kitchen }\end{array}$ & free & Direct \\
\hline $\begin{array}{l}\text { 9. Meeting room, Housing } \\
\text { association Midteggen }\end{array}$ & 1 room & $100 €$ & Direct \\
\hline
\end{tabular}


Parking spaces are available in Saupstad, but our interview-partners point out that free of charge parking time is very limited and parking costs are perceived as expensive. "Yes. But there are parking challenges. It may be something that you can change" (I3). Interviewees are afraid of getting a parking ticket, which is highly expensive (I5). Parking is especially important in the neighbourhood of Saupstad, where the public transportation is perceived as not sufficient by our interviewees and several of the participants at volunteer activities are older and dependent on the car to access the activity due to mobility challenges.

The interviewees who use shared spaces point out that from time to time they experience challenges in accessing the space for their voluntary activities with regard to entrance control. In the worst case the building or room was not accessible, and no one was available to help them. In cases like that, all further coordination is taken over by the voluntary manager. If the manager is not available, the voluntary event has to be cancelled. Other shared facilities are freely accessible, such as the clubhouse of the local football club: "We are always open, everybody can just come by" (I7) and makes it thereby easier for voluntaries to access and use those spaces.

\subsubsection{Needs and demands expressed to foster space sharing}

Regarding the spaces used for the voluntary activities, the interviewees point out several needs and demands. They express a wish for a centrally located building/centre for voluntary activities, with separate rooms for voluntary activities including a "meeting room and a cafeteria" (I4), and point to another voluntary centre in the neighbouring area of Kattem as best practise example: "They usually have, like at Kattem [another close-by neighbourhood], they have the café there, Kattem volunteer centre, where it is possible to buy food and they have showrooms" (I3). As a possible new location of the voluntary centre, they point at the local shopping centre which have spaces available, but the rental prices are perceived as very high by the interviewees.

Interviewees also point out that the current location of the voluntary centre is very hidden inside the building. "But no one comes from the street and into here to see if there are any volunteers. It's a little secluded" (I3). The proposed location within the shopping centre will give a higher visibility of voluntary activities. Regarding the coordination between voluntary activities and providers of spaces for them, interviewees ascertain that "the cooperation could be better" and that a shared vision for the neighbourhood of Saupstad is lacking (I7). The neighbourhood improvement program "områdeløft" is mentioned as one institution that could facilitate the development of a joint vision and commitment to neighbourhood development by several interviewees. Additionally, it is expressed that there is a "competition between the different volunteering organizations" and larger local organisations facilitating voluntary activities "are interested in having their own events" (I1). We recognize that this behaviour exists because the organizations compete for visibility and, consequently, membership.

During our interviews and observations, users of shared facilities express a need for spaces for private activities as e.g. family parties. For private social activities, the offer of spaces available is perceived as limited, as some of the shared spaces are only accessible for voluntary organisations, the space is perceived as too little, or kitchen facilities are not sufficient $(\mathrm{O} 2)$.

Table 3 gives a brief overview of factors influencing indoor room sharing in our case study of Sausptad, also pointing out the spatial level they are most applicable. 
Table 3: Overview of factors influencing indoor room sharing.

\begin{tabular}{|c|c|c|c|c|}
\hline Factor & Description & City & Neighbourhood & Building \\
\hline $\begin{array}{l}\text { Financial } \\
\text { aspects }\end{array}$ & $\begin{array}{l}\text { Costs for rent limit the availability } \\
\text { of spaces }\end{array}$ & & & $\mathrm{x}$ \\
\hline $\begin{array}{l}\text { Financial } \\
\text { aspects }\end{array}$ & $\begin{array}{l}\text { Incentives for public room sharing } \\
\text { foster availability of spaces }\end{array}$ & $\mathrm{x}$ & $\mathrm{x}$ & $\mathrm{x}$ \\
\hline Facilities & $\begin{array}{l}\text { Missing facilities limit the use of } \\
\text { spaces }\end{array}$ & & & $\mathrm{x}$ \\
\hline Location & $\begin{array}{l}\text { A good accessible location foster } \\
\text { use of spaces }\end{array}$ & & $\mathrm{x}$ & \\
\hline $\begin{array}{l}\text { Parking } \\
\text { availability }\end{array}$ & $\begin{array}{l}\text { Insufficient parking infrastructure } \\
\text { limit use of activities/spaces }\end{array}$ & & $\mathrm{x}$ & \\
\hline $\begin{array}{l}\text { Design of } \\
\text { buildings }\end{array}$ & $\begin{array}{l}\text { In equate location of rooms within } \\
\text { the building and possibilities for } \\
\text { multiple use and several use of } \\
\text { rooms at the same time }\end{array}$ & & & $\mathrm{x}$ \\
\hline $\begin{array}{l}\text { Entrance } \\
\text { control }\end{array}$ & $\begin{array}{l}\text { Need for a system that allows easy } \\
\text { access to spaces }\end{array}$ & & & $\mathrm{x}$ \\
\hline \multirow{2}{*}{$\begin{array}{l}\text { Information } \\
\text { and booking }\end{array}$} & $\begin{array}{l}\text { Through web-based online } \\
\text { platform }\end{array}$ & $\mathrm{x}$ & & \\
\hline & $\begin{array}{l}\text { Diverse channels for information } \\
\text { and booking, no central booking } \\
\text { system in place }\end{array}$ & & $\mathrm{x}$ & $\mathrm{x}$ \\
\hline
\end{tabular}

\section{DISCUSSION AND CONCLUSION}

Mapping the status of space sharing for voluntary activities has shown that there are different stakeholders with diverse roles and interests that are providing and facilitating space sharing in our case study of Trondheim. While Trondheim municipality is the largest provider of shared spaces for voluntary interests, their interest is to share their own spaces to foster voluntary activities. Providing shared spaces for neighbourhood activities is not prioritized by the booking platform and involved unit of Trondheim municipality, despite that our studies has shown how important the availability of geographically close shared spaces is for voluntary activities. Our in depth-study in the neighbourhood of Saupstad has shown that in addition to the city-wide booking platform, a lot of spaces are shared for voluntary activities through other channels. Additionally, rooms owned by the municipality are not included in the booking platform but facilitated for sharing through other, local channels. On a neighbourhood level, we recognize diverse reasons for sharing of spaces; financial reasons, the will to contribute to community life, as well as the hope to strengthen the ties and commitment to the institution sharing the space. While the voluntary centre has a central role in facilitating sharing of spaces, this is a fragile system as it is dependent on one person and his or her availability and resources. In Saupstad, sharing of spaces for voluntary activities is actively used and a variety of spaces are provided by diverse actors. But at the same time, this system seems intransparent as there are diverse routines to rent the spaces and no consistent booking and management system is in place.

Regarding the factors influencing the availability of shared spaces, we have identified several factors on building, neighbourhood and city-level. Some of these factors could be improved through organizational changes, as the revenue system implemented in Trondheim municipality has increased the availability of shared spaces. On the other hand, other factors 
such as the building design or entrance control can be changed only through physical changes in the built environment. We therefore see how important a long-term and holistic planning of the built environment is to foster community life through providing shared spaces for voluntary activities.

Our studies have shown the importance of the availability of shared spaces at a neighbourhood level for voluntary activities, and the broadness of the net of stakeholders that provide shared spaces on a neighbourhood level. At the same time, we raise the question: Who is or should be responsible for fostering and managing space sharing - both public and private - on a neighbourhood level to develop a resilient system to support community building through voluntary activities in shared spaces?

\section{ACKNOWLEDGEMENTS}

This research was conducted as part of the cooperation project "Sharing Neighbourhoods", funded by the Norwegian Research Council under the program BYFORSK (project 270737). The authors of this paper would like to thank all partners in Sharing Neighbourhoods as well as all participants involved through the presented case study.

\section{REFERENCES}

[1] SINTEF, Grunnskolebygg. Funksjoner og arealer. Byggforskseriens anvisning 342.205, SINTEF Press, 2009.

[2] Coleman, J.S., Social capital in the creation of human capital. American Journal of Sociology, 94, pp. 95-120, 1988.

[3] Dempsey, N., Bramley, G., Power, S. \& Brown, C., The social dimension of sustainable development: Defining urban social sustainability. Sustainable Development, 19(5), pp. 289-300, 2011.

[4] Putnam, R.D., Making Democracy Work: Civic Traditions In Modern Italy, Princeton University Press: Princeton, 1993.

[5] Hall, P.A., Social capital in Britain. British Journal of Political Science, 29, pp. 417-461, 1999.

[6] Maloney, W., Smith, G. \& Stoker, G., Social capital and urban governance: Adding a more contextualised top-down perspective. Political Studies, 48, pp. 802-820, 2002.

[7] Wilson, J., Volunteering. Annual Review of Sociology, 26(1), pp. 215-240, 2000.

[8] Lee, Y.J. \& Brudney, J.L., Participation in formal and informal volunteering: Implications for volunteer recruitment. Nonprofit Management and Leadership, 23(2), pp. 159-180, 2012.

[9] Kendall, J. \& Knapp, M., The Voluntary Sector in the UK, Manchester University Press: Manchester, 1996.

[10] Salamon, L., Partners in Public Service, John Hopkins University Press: Baltimore, 1995.

[11] Hooghe, M. \& Botterman, S., Urbanization, community size, and population density: Is there a rural-urban divide in participation in voluntary organizations or social network formation? Nonprofit and Voluntary Sector Quarterly, 41, pp. 120-144, 2012.

[12] Musick, M. \& Wilson, J., Volunteers: A Social Profile, Indiana University Press: Bloomington, 2008.

[13] Dury, S., Willems, J., De Witte, N., De Donder, L., Buffel, T. \& Verté, D., Municipality and neighborhood influences on volunteering in later life. Journal of Applied Gerontology, 35(6), pp. 601-626, 2016.

[14] Oldenburg, R., The Great Good Place, Hachette, 1989. 
[15] Voelker, B., Flap, H. \& Lindenberg, S., When are neighbourhoods communities? Community in Dutch neighbourhoods. European Social Review, 23(1), pp. 99-114, 2007.

[16] Oldenburg, R., Our vanishing “Third places". Planning Commissioner Journal, 25, 1997.

[17] Butler, D. \& Diaz, C., "Third places" as community builders. Available at: https://www.brookings.edu/blog/up-front/2016/09/14/third-places-as-communitybuilders/. Accessed on: 16 Jun. 2019.

[18] Mayring, P., Qualitative content analysis. Forum: Qualitative Social Research, 1(2), 2000.

[19] Bratberg, T., Trondheim byleksikon. Kunnskapsforlaget, p. 456, 1996.

[20] Trondheim Municipality, Områdeprogram for Saupstad-Kolstad 2013-2020, 2013.

[21] Rørtveit, H.N., «Genialt planlagt?» Drabantbyen som hjem i spennet mellom boligfaglige idealer og levde landskap. NTNU Universitetsforlag: Trondheim, 2015.

[22] Trondheim Municipality, Reglement for utlån av kommunale lokaler, 2014.

[23] Trondheim Municipality, Bookingbase, www.trondheim.kommune.no/tema/kulturog-fritid/lokaler1/lokaler/. Accessed on: 13 Jan. 2020. 